\title{
Solarium use in Australia, recent trends and context
}

\author{
Kate Francis \\ Problem Gambling Research and Treatment Centre, University of Melbourne, \\ Victoria
}

\section{Suzanne Dobbinson, Melanie Wakefield \\ Centre for Behavioural Research in Cancer, Cancer Council Victoria}

\author{
Afaf Girgis \\ Centre for Health Research \& Psycho-Oncology, Cancer Council NSW, University of \\ Newcastle \& Hunter Medical Research Institute, New South Wales
}

f n Australia, more than 1,600 people die from skin cancer each year. ${ }^{1}$ Solaria emit high levels of UV radiation (UVR). ${ }^{2}$ Two systematic reviews have reported that the use of solaria is related to increased risk of melanoma and squamous cell carcinoma, ${ }^{3,4}$ with elevated risk of melanoma for solarium use under the age of 35 years.

Between 1996 and 2006, Australian consumers' demand for solaria appeared to be increasing, indicated by a $319 \%$ increase in solarium listings in capital city telephone books. ${ }^{5}$ State-based studies (in Queensland, New South Wales and Victoria) conducted across different years reported that between $1.3 \%$ and $3.0 \%$ of adults ${ }^{6-8}$ and in New South Wales $12.4 \%$ of adolescents ${ }^{9}$ had used a solarium within the previous year. This brief report describes the findings of the first two national surveys that examined Australian adolescents' and Australian adults' use of solaria recent trends in prevalence, and context.

\section{Methods}

Data were gathered as part of a national skin cancer prevention survey established in summer $2003 / 04^{10}$ and repeated in 2006/07 using equivalent methods. In each survey a representative sample of Australian adolescents (12-17) and adults (18-69) were recruited via weekly crosssectional telephone calls on Mondays and
Tuesdays following eight summer weekends to randomly selected households with a landline telephone. Respondents were informed that the survey was 'about people's attitudes towards being out in the sun' and that 'the opinion of people aged 12 to 69' was being sought. Parental permission was requested for respondents under 16. The key questions relating to solaria included:

1) Have you ever used a solarium?

2) Have you been to a solarium in the last 12 months?

3) During the last 12 months how many times did you attend?

4) Thinking about the last time you went to a solarium, what prompted you to go?

Demographic information collected included: age, gender, and skin sensitivity to sunburn. Preference for a tan was assessed by the question Do you like to get a suntan or not? Respondents' opinions on tanning were also sought with agreement or disagreement to six statements recorded on a 5-point likert scale.

The analysis was conducted following application of population weights to adjust for over-sampling of respondents in smaller states and territories, and minor variations by age, gender, city/country residence. Univariate statistics were used to describe the prevalence of solarium use for adults and adolescents in both surveys. A comparison of the prevalence of adults' solarium use in 2003/04 and 2006/07 was examined via logistic regression using two dichotomous

\author{
Abstract \\ Objectives: To describe the prevalence \\ of solarium use among representative \\ samples of Australian adolescents (12-17 \\ years) and adults (18-69 years).
}

Methods: In national surveys conducted in 2003/04 and 2006/07 using equivalent methods, $n=11,509$ Australian adolescents and adults self-reported their use of solaria.

Results: In 2006/07 $10.6 \%$ of adults had 'ever' used a solarium, and use was most prevalent among women aged 18 to $24(17.1 \%)$ and 25 to $44(20.7 \%)$. Few adolescents $(2.5 \%)$ had ever used a solarium. The prevalence of past year use was much lower $(0.6 \%$ of adolescents, $1.5 \%$ of adults) and there was a significant reduction among adults between surveys (OR=0.69, 95\% Cl=0.52-0.94). Adults' attitudes related to past year solarium use were preference for a suntan $(\mathrm{OR}=4.68$, 95\% Cl=2.48-8.85); perceived protan attitudes of peers (OR=2.10, 95\% $\mathrm{Cl}=1.17-3.77$ ), belief that a suntan looks healthy $(\mathrm{OR}=1.92,95 \% \mathrm{Cl}=1.09-3.39)$; and perceiving they have some risk of getting skin cancer (OR=1.69, 95\% $\mathrm{Cl}=1.03-2.78$ ).

Conclusions and implications: Although solarium use in Australia is relatively low, it is highest among young adult women. These data show encouraging downward trends in use, and provide a foundation for monitoring the impact of forthcoming regulatory changes to the solarium industry.

Key words: solaria, adults, adolescents, tanning, sun beds.

Aust NZ J Public Health. 2010; 34:427-30 doi: 10.1111/j.1753-6405.2010.00578.x 
dependent variables 'ever used' and 'recent solarium use' adjusting for the covariates age, gender and skin-type. Unadjusted prevalence figures are reported to describe the trends in adolescents' solarium use. Additional analyses examined the context of adults' solarium use in 2006/07. Univariate statistics were used to describe frequency and reported reasons for use, while the relationship between adults' beliefs and solarium use were examined using logistic regression adjusting for age, gender and skin type.

\section{Results}

In total, 11,509 respondents were interviewed across the two surveys and response rates were $24 \%$ in $2003 / 04$ and $16 \%$ in $2006 / 07$. The two samples were broadly representative of the estimated resident Australian population aged 12 to $69^{11,12}$ in terms of age, sex, and state. At least two-thirds of respondents in both periods had either highly or moderately sunburn-sensitive skin. Among adolescents $66.2 \%$ in $2003 / 04$ and $66.8 \%$ in $2006 / 07$ reported they would burn only or burn then tan after 30 minutes strong sunshine in spring. Among adults $76.6 \%$ in 2003/04 and $74.6 \%$ in $2006 / 07$ reported highly or moderately sunburn-sensitive skin.

In $2006 / 07,2.5 \%(n=16)$ of adolescents reported ever having used a solarium. Only girls aged 15 to 17 reported using one within the last 12 months (Table 1). Adolescents' solarium use was also low in 2003/04, with $3.4 \%(n=24)$ reporting they ever used a solarium and $1.2 \%(n=9)$ within the last 12 months. Solarium use was more common among adults, with $10.6 \%(\mathrm{n}=539)$ reporting they had ever used a solarium in $2006 / 07$, and $1.5 \%(n=78)$ within the 12 months prior to interview. The highest reported ever use of solaria was among women aged 25 to 44 years at $20.7 \%$, and was also high among women aged 18 to 24 (17.1\%). Women aged 18 to 24 years also had the highest prevalence $(6.7 \%)$ of use in the last 12 months.

A similar pattern of solarium use by age and gender was noted for 2003/04 (Table 1). Logistic regression analyses showed there was little change in the percentage of adults who had ever used a solarium between surveys $(10.9 \%$ to $10.6 \%$; OR $=0.96,95 \%$ $\mathrm{CI}=0.85,1.10)$. There was evidence of a decrease in adults' solarium use within the last 12 months $(2.2 \%$ to $1.5 \%$; OR $=0.69$, $95 \% \mathrm{CI}=0.52,0.94)$.

In 2006/07 the majority of adults who reported having used a solarium in the last 12 months $(n=78)$ had attended several times within the year with $15 \%(\mathrm{n}=11)$ having been 25 times or more, $50 \%(n=39)$ had been 5 to 24 times. The main reported reasons adults in 2006/07 gave for their most recent use of a solarium $(\mathrm{n}=539)$ were preparing for a special event or holiday $(30.6 \%)$, vanity/ to get a tan/ I'm too pale (19.9\%) and fading $\tan (15.2 \%)$.

A number of adults' attitudes and beliefs about tanning were associated with having ever used a solarium and with recent solarium use (Table 2). Adults who reported they liked to get a suntan were three times more likely to have ever used a solarium and approximately five times more likely to have used one in the last 12 months, when compared with adults who did not like to get a tan. Similarly, adults who believed a suntanned person looks more healthy were more likely to have used a solarium ever or within the last 12 months compared to those who did not agree that a tan looks more healthy. Adults who believed that their friends think a suntan is a good thing were twice as likely to report solarium use in the last 12 months than those who did not hold this belief. Adults' perceived risk of getting skin cancer was also associated with adults' solarium use.

\section{Discussion}

Overall, the study found a low prevalence of solarium use in Australia in 2006/07 except among young adult women. However, there was some evidence of a small decrease in recent solarium use among adults.

The levels of solarium use for adults were generally consistent with the few state-based surveys. ${ }^{6-8}$ The national figures for adolescents were somewhat lower than the figure reported for NSW school students' solarium use (12\% within the last 12 months), ${ }^{9}$ but even these figures were much lower than reported for the US

Table 1: Adolescent and adult use of solaria in $2003 / 04$ and $2006 / 07$, as a function of age and gender of participants (weighted data).

\begin{tabular}{|c|c|c|c|c|c|c|c|c|c|}
\hline \multirow[b]{2}{*}{ Adolescents } & & \multicolumn{2}{|c|}{$\begin{array}{c}\text { Ever used a } \\
\text { solarium 2003/04 }\end{array}$} & \multicolumn{2}{|c|}{$\begin{array}{c}\text { Ever used a } \\
\text { solarium 2006/07 }\end{array}$} & \multicolumn{2}{|c|}{$\begin{array}{c}\text { Used a solarium in } \\
\text { last } 12 \text { months } 2003 / 04\end{array}$} & \multicolumn{2}{|c|}{$\begin{array}{l}\text { Used a solarium in } \\
\text { last } 12 \text { months } 2006 / 07\end{array}$} \\
\hline & & $\mathrm{N}$ & $\%$ & $\mathrm{~N}$ & $\%$ & $\mathrm{~N}$ & $\%$ & $\mathrm{~N}$ & $\%$ \\
\hline Overall & & $24 / 699$ & 3.4 & $16 / 652$ & 2.5 & $9 / 699$ & 1.2 & $4 / 652$ & 0.6 \\
\hline \multirow[t]{2}{*}{ Age } & 12 to $14 \mathrm{yrs}$ & $8 / 351$ & 2.3 & $6 / 329^{a}$ & 1.8 & $1 / 352^{a}$ & 0.3 & $0 / 328$ & 0 \\
\hline & 15 to $17 \mathrm{yrs}$ & $16 / 348$ & 4.6 & $10 / 324$ & 3.1 & $8 / 348$ & 2.3 & $4 / 324$ & 1.2 \\
\hline \multirow[t]{2}{*}{ Sex } & Male & $10 / 358$ & 2.8 & $5 / 334$ & 1.5 & $1 / 358$ & 0.3 & $0 / 334$ & 0 \\
\hline & Female & $13 / 340^{\mathrm{a}}$ & 3.8 & $11 / 319^{a}$ & 3.4 & $8 / 341$ & 2.3 & $4 / 318$ & 1.3 \\
\hline Adults & & & $\%$ & & $\%$ & & $\%$ & & $\%$ \\
\hline Overall & & $555 / 5,073$ & 10.9 & $539 / 5,085$ & 10.6 & $110 / 5,073$ & 2.2 & $78 / 5,085$ & 1.5 \\
\hline \multirow[t]{3}{*}{ Age } & 18 to $24 \mathrm{yrs}$ & $74 / 741^{a}$ & 10.0 & $76 / 737^{a}$ & 10.3 & $29 / 740$ & 3.9 & $31 / 736$ & 4.2 \\
\hline & 25 to $44 \mathrm{yrs}$ & $346 / 2,246$ & 15.4 & $304 / 2,199$ & 13.8 & $70 / 2,246$ & 3.1 & $38 / 2,199$ & 1.7 \\
\hline & 45 to $69 \mathrm{yrs}$ & $136 / 2,087$ & 6.5 & $159 / 2,150$ & 7.4 & $11 / 2,087$ & 0.5 & $10 / 2,150$ & 0.5 \\
\hline \multirow[t]{2}{*}{ Sex } & Male & $164 / 2,538$ & 6.5 & $139 / 2,550$ & 5.5 & $33 / 2,538$ & 1.3 & $24 / 2,550$ & 0.9 \\
\hline & Female & $391 / 2,535$ & 15.4 & $399 / 2,535$ & 15.7 & $77 / 2,535$ & 3.0 & $54 / 2,535$ & 2.1 \\
\hline
\end{tabular}

Notes: a) Some n/figures do not round exactly due to weighting. 
and northern Europe. ${ }^{13,14}$ Nonetheless, public health advocates will be concerned that some Australians were undergoing intense regular exposure to artificial UVR in solaria and that a number of adolescents had accessed and used solaria.

Although the characteristics of tanning bed users have been studied in the US ${ }^{14-16}$ and Europe ${ }^{17,18}$ there have been few such studies in Australia. ${ }^{6,19}$ The findings that Australian solarium users were more likely than non-users to place a high value on a tan, perceive it looks healthy and perceive a high risk of getting skin cancer are not surprising. These associations suggest that interventions that focus on alternatives for improving appearance including use of fake tans ${ }^{20}$ or resisting peer pressure and improving self-efficacy to reverse perceptions that skin cancer risk is inevitable, may be worth further trial to attempt to reduce solarium use among young women in particular.

The observed decline in the prevalence of recent solarium use nationally between 2003/04 and 2006/07 occurred coincidentally with an intensive national skin cancer campaign on TV in 2006, and boosted in some states by extra campaigns. The strong correlation of solarium use and social norms suggests that skin cancer prevention campaigns may well influence solarium use by lessening the social acceptability of tanning, as the amount of exposure to skin cancer prevention television advertising is associated with improvements in public attitudes to tans. ${ }^{21}$

Study limitations include the low response rate, which can be attributed to timing constraints of the interviews and decline in response to telephone surveys more generally. ${ }^{22,23}$ Our findings predate the widespread publicity about the dangers of solarium use by Clare Oliver and the later introduction of state-based regulations on solaria. ${ }^{24,25}$ These data relate to a time of rapid increase in the number of solaria operating in Australia. ${ }^{5}$ Thus, lower rates of solarium use by the population might be already anticipated in line with the altered regulatory environment. Nevertheless, these new state-based regulations (banning people under 18 and people with fair skin (Fitzpatrick Skin type I) ${ }^{26,27}$ would not prevent an adult with skin type II that burns easily and tans minimally, or less sensitive skin types (II or IV) with propensity to tan using solaria. ${ }^{25}$ There may also be unintended effects on patronage, if people perceive the regulations make solaria safer. Moreover, as the intense media on Clare Oliver's death subsides resurgence in solarium tanning may occur. Access to solaria is still a concern as while limits on frequency and length of sessions, hygiene standards and provision of protective eyewear are newly regulated, ${ }^{25}$ solaria may still emit levels of UVR three times higher than midday summer sun. ${ }^{27,3}$

It is important to evaluate the public health impact of these substantial regulatory changes to ensure that they are effective in reducing people's use of these artificial UVR sources for tanning. Future studies need to monitor industry compliance with regulations and advertising practices and to assess the impact on actual solaria use, with the present study providing a valuable baseline for future comparisons.

\section{Acknowledgements}

This study was funded by the state Cancer Councils, Cancer Council Australia, and Cancer Australia. We acknowledge the work of the national sun protection survey research committee, including Prof. David Hill (chair), Prof. Joanne Aitken, and Dr Anthony Reeder; and also Kelly-Ann Bowles, Andrew Fairthorne and Kris Jamsen for their preliminary analysis of the survey data.

Table 2: Adult solarium users' versus non-users' attitudes and beliefs regarding sun tanning and skin cancer, 2006/07 sample $(\mathrm{N}=5,085)$.

\begin{tabular}{|c|c|c|c|c|c|c|c|c|}
\hline & \multicolumn{4}{|c|}{$\begin{array}{l}\text { Ever used a solarium } \\
\qquad(2006 / 07)\end{array}$} & \multicolumn{4}{|c|}{$\begin{array}{l}\text { Used solarium in last } 12 \text { months } \\
\qquad(2006 / 07)\end{array}$} \\
\hline & $\begin{array}{l}\text { No } \\
(\%)\end{array}$ & $\begin{array}{l}\text { Yes } \\
(\%)\end{array}$ & $\begin{array}{r}\text { Adjusted } \\
\text { Odds }\end{array}$ & $95 \% \mathrm{Cl}$ & $\begin{array}{l}\text { No } \\
(\%)\end{array}$ & $\begin{array}{l}\text { Yes } \\
(\%)\end{array}$ & $\begin{array}{r}\text { Adjusted } \\
\text { Odds }\end{array}$ & $95 \% \mathrm{Cl}$ \\
\hline & & & Ratio $^{a}$ & & & & Ratio & \\
\hline Like to get a tan (yes) & 28.5 & 58.9 & 2.97 & 2.41-3.66 & 30.9 & 80.8 & 4.68 & $2.45-8.85$ \\
\hline \multicolumn{9}{|l|}{ Beliefs about suntans } \\
\hline A suntanned person looks more healthy (agree) & 44.2 & 62.9 & 1.69 & $1.37-2.08$ & 45.8 & 71.8 & 1.92 & $1.09-3.39$ \\
\hline A suntanned person is more healthy (agree) & 12.1 & 14.7 & 1.09 & $0.81-1.46$ & 12.2 & 23.1 & 1.56 & $0.86-2.85$ \\
\hline \multicolumn{9}{|l|}{ Perceived social norms } \\
\hline Close family think a suntan is a good thing (agree) & 22.5 & 29.7 & 1.09 & $0.86-1.38$ & 23.0 & 39.7 & 0.96 & $0.57-1.61$ \\
\hline Friends think a suntan is a good thing (agree) & 36.3 & 44.6 & 0.95 & $0.76-1.18$ & 36.6 & 73.1 & 2.10 & 1.17-3.77 \\
\hline \multicolumn{9}{|l|}{ Beliefs about skin cancer } \\
\hline There is little chance I will get skin cancer (disagree) & 52.9 & 59.9 & 1.30 & $1.07-1.58$ & 53.5 & 65.4 & 1.69 & $1.03-2.78$ \\
\hline $\begin{array}{l}\text { If I regularly protect myself from the sun, I can avoid } \\
\text { skin cancer (disagree) }\end{array}$ & 12.8 & 13.5 & 1.12 & $0.84-1.49$ & 12.9 & 7.7 & 0.65 & $0.25-1.71$ \\
\hline
\end{tabular}

Notes: \% Unadjusted weighted percentages.

a) Results of logistic regression model predicting ever used a solarium adjusting for age, gender, and skin-type. $n=4,939$, Nagelkerke $R^{2}=0.158$, Hosmer Lemeshow $p>0.05$.

b) Results of logistic regression model predicting used a solarium last 12 months, adjusting for age, gender, and skin-type. $n=4,939$, Nagelkerke $R^{2}=0.206$, Hosmer Lemeshow $p>0.05$.

The models excluded 'state' as a covariate, given limited data for smaller states/territories (NT, ACT, Tas) and state-based population weights were applied to these data. 


\section{References}

1. Australian Institute of Health and Welfare. State and Territories GRIM (General Record of Incidence of Mortality) Books. Canberra (AUST): AIHW; 2005.

2. Standards Australia, Standards New Zealand. Australian/New Zealand Standard: Solaria for Cosmetic Purposes. Sydney (AUST): AS/NZS; 2002 March 29. Report No.: 2635:2002.

3. Gordon L, Hirst N. The Health Effects of Using Solaria and Potential Costeffectiveness of Enforcing Solaria Regulations in Australia. Canberra (AUST): Australian Radiation Protection and Nuclear Safety Agency; 2007. [cited 2008 Jan 16]. Available from: http://www.arpansa.gov.au/pubs/rhc/QIMR_solaria07. pdf

4. International Agency for Research on Cancer Working Group on artificial ultraviolet light and skin cancer. The association of use of sunbeds with cutaneous malignant melanoma and other skin cancers: A systematic review [Published erratum in: Int J Cancer 2007;120:2526]. Int J Cancer. 2007;120:1116-22.

5. Makin JK, Dobbinson SJ, Herd NL. The increase in solariums in Australia, 1992-2006. Aust NZ J Public Health. 2007;31:191-2.

6. Lawler SP, Kvaskoff M, DiSipio T, Whiteman D, et al. Solaria use in Queensland, Australia. Aust NZ J Public Health. 2006;30:479-82.

7. Centre for Epidemiology and Research. New South Wales Population Health Survey: 2005 Report on Adult Health. Sydney (AUST): New South Wales Department of Health; 2006.

8. Dobbinson S. Reaction to the 2000/2001 SunSmart Campaign: Results from a Telephone Survey of Victorians. Melbourne (AUST): The Cancer Council Victoria; 2004. SunSmart Research and Evaluation Studies No.: 7.

9. Centre for Epidemiology and Research. New South Wales School Students Health Behaviours Survey: 2005 Report. Sydney (AUST): New South Wales Department of Health; 2007.

10. Dobbinson S, Wakefield M, Hill D, Girgis A, Aitken JF, Beckmann K, et al. Prevalence and determinants of Australian adolescents' and adults' weekend sun protection and sunburn, summer 2003-2004. JAm Acad Dermatol. 2008;59:602-14.

11. Australian Bureau of Statistics. 3235.0.55.001 Population by Age and Sex, Australia - Electronic Delivery, Jun 2003. Canberra (AUST): ABS; 2003.

12. Australian Bureau of Statistics. 3235.0.55.001 Population by Age and Sex, Australia Jun 2005 - Electronic Delivery, Jun 2005. Canberra (AUST): ABS; 2005.

13. Lazovich D, Forster J. Indoor tanning by adolescents: prevalence, practices and policies. Eur J Cancer. 2005;41:20-27.
14. Cokkinides V, Weinstock M, Lazovich D, Ward E, Thun M. Indoor tanning use among adolescents in the US, 1998 to 2004. Cancer. 2009;115:190-8.

15. Demko CA, Borawski EA, Debanne SM, Cooper KD, Stange KC. Use of indoor tanning facilities by white adolescents in the United States. Arch Pediatr Adolesc Med. 2003;157:854-60.

16. Cokkinides VE, Weinstock MA, O'Connell MC, Thun MJ. Use of indoor tanning sunlamps by US youth, ages 11-18 years, and by their parent or guardian caregivers: prevalence and correlates. Pediatrics. 2002;109:1124-30.

17. Boldeman C, Jansson B, Dal H, Ullen H. Sunbed use among Swedish adolescents in the 1990s: a decline with an unchanged relationship to health risk behaviors. Scand J Public Health. 2003;31:233-7.

18. de Vries H, Lezwijn J, Hol M, Honing C. Skin cancer prevention: behaviours and motives of Dutch adolescents. Eur J Cancer Prev. 2005;14:39-50.

19. Paul CL, Girgis A, Tzelepis F, Walsh RA. Solaria use by minors in Australia: is there a cause for concern? Aust NZ J Public Health. 2004;28:90.

20. Chapman S. Faking it: should cancer control agencies promote "fake" tanning lotions? Med J Aust. 1999; 170:603-4.

21. Dobbinson SJ, Wakefield MA, Jamsen KM, Herd NL, Spittal MJ, Lipscomb JE, et al. Weekend sun protection and sunburn in Australia: trends (1987-2002) and association with SunSmart television advertising. Am JPrev Med. 2008;34:94-101.

22. Link MW, Battaglia MP, Frankel MR, Osborn L, Mokdad AH. Address-based versus random-digit-dial surveys: comparison of key health and risk indicators. Am J Epidemiol. 2006;164:1019-25.

23. Boland M, Sweeney MR, Scallan E, Harrington M, Staines A. Emerging advantages and drawbacks of telephone surveying in public health research in Ireland and the U.K. BMC Public Health. 2006;6:208.

24. Jalleh G, Donovan RJ, Lin C, Slevin T. Changing perceptions of solaria and cancer risk: the role of the media. Med J Aust. 2008;188:735.

25. MacKenzie R, Imison M, Chapman S, Holding S. Mixed messages and a missed opportunity: Australian news media coverage of Clare Oliver's campaign against solaria. Med J Aust. 2008;189:371-4.

26. Weinstock MA. 1992 Assessment of sun sensitivity by questionnaire: validity of items and formulation of a prediction rule. J Clin Epidemiol. 1992;45:547-52.

27. Standards Australia/Standards New Zealand. Australian/New Zealand Standard: Solaria for Cosmetic Purposes. Sydney (AUST): AS/NZS; 2008. Report No.: 2635:2008.

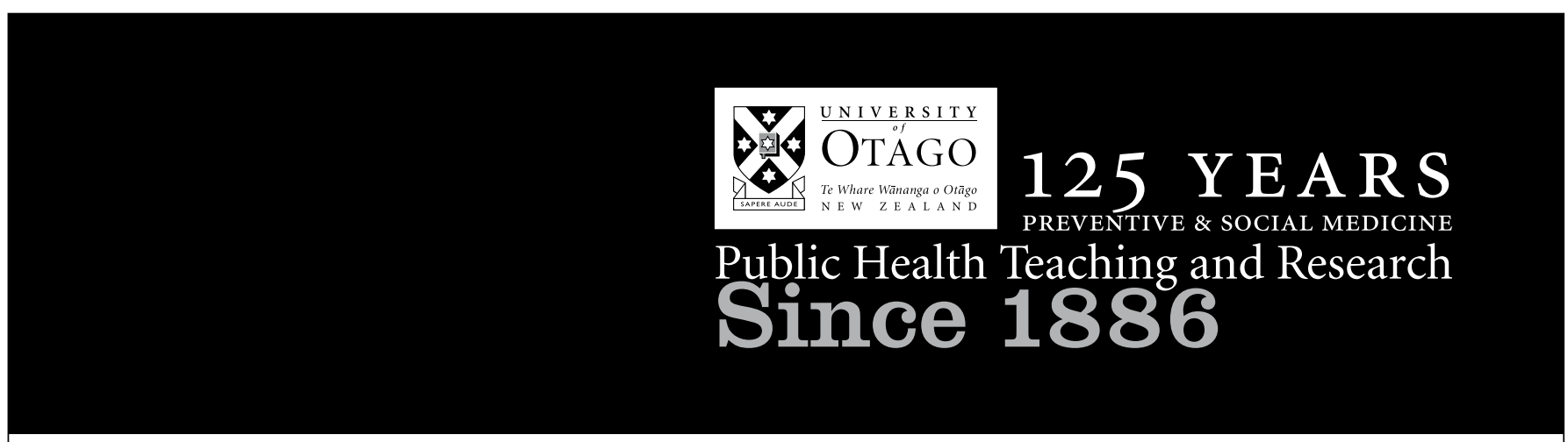

University of Otago

Department of Preventive and Social Medicine I25th Anniversary Celebrations 4-6 March 2OII

\section{We invite you to join us to celebrate the Department's history and toast its future.}

\section{FRIDAY 4 MARCH}

pm Today's Department: achievement and emerging research

evening Welcome and launch of the Departmental History

\section{SATURDAY 5 MARCH}

all day Conference on Reproductive Health in honour of Professor Sir David Skegg, Head of Department $1980-2004$

evening Quasquicentennial Dinner

\section{SUNDAY 6 MARCH}

pm Lunch followed by the Great Healthy Film Show

To register interest please go to www.otago.ac.nz/dsm/psm 